\title{
Correction to: The Great Barrier Reef and Coral Sea
}

Tom C.L. Bridge, Robin J. Beaman, Pim Bongaerts,

Paul R. Muir, Merrick Ekins, and Tiffany Sih

\section{Correction to:}

Chapter 20 in: Y. Loya et al. (eds.), Mesophotic Coral Ecosystems, Coral Reefs of the World 12, https://doi.org/10.1007/978-3-319-92735-0_20

The original online version of this chapter was inadvertently published with incorrect initials of the author of the Chapter 20 as Tom L.L. Bridge. The correct name of this author is Tom C.L. Bridge. This has now been corrected. 